\title{
An Analysis on the Moisture and Thermal Protective Performance of Firefighter Clothing Based on Different Layer Combinations and Effect of Washing on Heat Protection and Vapour Transfer Performance
}

\author{
Ozgur Atalay, Senem Kursun Bahadir, and Fatma Kalaoglu \\ Istanbul Technical University, Faculty of Textile Technologies and Design, Inonu Cad No. 65, Gumussuyu, \\ Beyoglu, 34437 Istanbul, Turkey \\ Correspondence should be addressed to Ozgur Atalay; atalayoz@itu.edu.tr
}

Received 21 September 2015; Revised 30 November 2015; Accepted 6 December 2015

Academic Editor: Peter Chang

Copyright (c) 2015 Ozgur Atalay et al. This is an open access article distributed under the Creative Commons Attribution License, which permits unrestricted use, distribution, and reproduction in any medium, provided the original work is properly cited.

\begin{abstract}
Fabric assemblies for firefighting clothing have been tested for heat protection and comfort. The constituent materials and fabric structures have been specifically selected and tailored for firefighters' clothing. In order to do this, four types of outer shell fabrics, four types of moisture barrier fabrics, and four types of heat barriers with different weights and material compositions were used to make a multilayered fabric assembly. Heat transfer (flame), heat transfer (radiant), and water vapour resistance tests were conducted according to the latest EN469 test standard which also recommends washing tests. These tests reveal that material content and material brand have considerable effect on the required performance levels of heat protection. In addition, while washing tests have improved water vapor transfer properties, they have a deteriorating effect on heat protection performance. Considering heat protection and moisture comfort properties, the optimal assemblies are thereby identified.
\end{abstract}

\section{Introduction}

Body temperature is one of the four vital signs that are standard in medical settings along with heart rate, blood pressure, and respiratory rate. Vital signs are measurements of the physiological condition of the human body and reveal the body's ability to regulate body temperature, maintain blood flow, and oxygenate body tissues [1].

Thermal stress generally occurs due to a failure of the thermoregulatory system to keep body core temperature within its boundaries [2]. Thermal stress is not caused by any diseases but results from a combination of various factors such as extra metabolic heat generation within the body during exercise, prolonged exposure to an extremely hot thermal environment (high air and radiant temperature and high humidity), low air velocity, and reduced evaporation of sweat [3]. When the body becomes unable to cool itself, heatinduced illness such as heat stress and heat exhaustion may result.
The level of the heat and vapour transfer rate from the human body to the outer environment determines heat stress. In addition to this, heat capacity and moisture absorption also have effect on heat stress. The parameters affecting this rate are thermal resistance (Rct) and moisture vapour resistance (Re) [4]. At this stage, if the situation is not treated quickly, it may lead to a deadly form of heat illness called heat stroke which might occur when the core body temperature exceeds $40^{\circ} \mathrm{C}[5,6]$.

The aforementioned scenario is a big concern for people who are exposed to heat for prolonged periods of time and this applies generally to firefighters due to their working conditions. Normally, the human body makes adjustments in the vasomotor tone in order to retain its core body temperature $[7,8]$. If these adjustments are not enough to maintain the temperature within its set limits, additional mechanisms, such as sweating, are initiated [9]. It is also found that when the human body is exposed to radiant heat at the level of $4 \mathrm{~kW} / \mathrm{m}^{2}$, second-degree burn occurs in 30 
TABLE 1: Requirement for the heat and moisture transfer property of firefighter turnout clothing in EN469 Standard: 2014.

\begin{tabular}{llccc}
\hline Property & Index or factor & $\begin{array}{c}\text { Level 1 } \\
\text { requirement }\end{array}$ & Marking & $\begin{array}{c}\text { Level 2 } \\
\text { requirement }\end{array}$ \\
\hline Heat transfer (flame) & $\mathrm{HTI}_{24}$ & $\geq 9.0$ & & $\geq 13.0$ \\
& $\mathrm{HTI}_{24-12}$ & $\geq 3.0$ & $X 1$ & $\geq 4.0$ \\
Heat transfer (radiant) & $\mathrm{RHTI}_{24}$ & $\geq 10.0$ & & $\geq 18.0$ \\
& $\mathrm{RHTI}_{24-12}$ & $\geq 3.0$ & $Z 1$ & $\leq 30 \mathrm{~m}^{2} \mathrm{~Pa} / \mathrm{W}$ \\
Water vapor resistance & & $>30-\leq 45 \mathrm{~m}^{2} \mathrm{~Pa} / \mathrm{W}$ & $Z 2$ \\
\hline
\end{tabular}

HTI: Heat Transfer Index.

seconds [10]. Thus, when clothing is designed for firefighters, it should not only offer flame resistance but also allow a high level of wearing comfort in terms of allowing vapor transfer from the body to reduce the excessive heat on human body. Not only the protective performance of the clothing is greatly dependent on the presence of moisture, but also the thermal protection of the clothing is also affected by the amount of moisture and its distribution, types of materials used for the clothing system and the design of clothing, and the level of thermal intensity [11-13]. Accumulated moisture on the human skin and in the fabric ensembles can alter the level of protection. In one study, it was proven that moisture has both positive and negative effects on the thermal protection performance of the protective clothing [14]. The presence of moisture in the clothing system can actually improve the thermal protection under low radiant [15].

Typical protective firefighter clothing is made of three different layers [16]. The outer layer of the structure is flameresistant material that is generally constructed through the application of a flame retardant finish [17] and extrusion with flame retardant additives [18] or by using inherently flame resistant materials. The use of inherently flame resistant materials does not require any additional process or additives [19]. On the other hand, these fibers are generally blended with other fibers in order to reduce production costs and improve comfort properties. These high performance flame retardant fibers include organic materials but are not limited to aramid including $\mathrm{p}$-aramid and $\mathrm{m}$-aramid (polyimide (PI), polybenzimidazole $(\mathrm{PBI})$, polyethylene-2,6-naphthalate (PEN), and p-phenylene-2,6-benzobisoxazole (PBO)) [20]. A recent study showed that when the $\mathrm{p}$-aramid content of the structure increases, it has a negative impact on the flame-resistant properties of the structure. Thus, it was found that a p-aramid content of the structure between $5 \%$ and $23 \%$ has optimum properties in terms of flame resistance [21]. The moisture barrier of the structure is the middle layer and prevents high temperature water vapor, chemicals, and other pathogens from entering the clothing. Woven or nonwoven backing substrate with a permeable film layer is generally used as a moisture barrier [22]. The third layer of the clothing is a thermal liner that provides thermal protection for the wearer with its nonwoven or porous padding structure [12].

The flame retardant property is the main concern for firefighter clothing. In addition to this, comfort properties are also crucial for improving the wearer's performance and the reduction of heat stress related issues. Weight and materials combinations are important parameters in order to optimize functional properties as well as comfort properties. Thus, some studies have focused on the evaluation of these parameters. According to Mandal et al. the protective performance of the clothing system in flame and heat exposures is dependent on the absorptivity and thermal insulation of the fabric system [23]. Cui and Zhang found that the outer shell and the moisture barrier have significant effects on the TPP rating of assemblies [24]. They measured thermal protection performance and vapor transmission rate on the basis of 16 different combinations and found the optimum variation. In another study, it was revealed that material weight and thickness have a direct impact on the moisture vapor resistance value and they matched different materials in order to maintain a balance between heat and vapor transfer [25]. Keiser et al. also found that the moisture content of a single layer is not only dependent on the material properties of that particular layer but mainly on the properties of the neighboring layers or even of the whole combination [26]. Thus, it is crucial to test the whole assembly instead of testing individual layers of the protective clothing structure. Song et al. also examined multilayer fabrics by analyzing stored thermal energy in multilayer fabrics and thermal protective performance of clothing. The study revealed that while multilayers provided a better insulation, a large amount of thermal energy may be stored in the system because of this structure, potentially causing skin burn injuries [27].

Heat transfer occurs by thermal radiation, convection, and conduction or a combination of these mechanisms [28]. Firefighters spend about $5-10 \%$ of their duty time exposed to extreme heat and flame [29]. Thus, radiant or convective heat causes major hazards during the firefighting. As known, applied standards for firefighting clothing vary depending on the region. Thus, requirements for US, EU, or other parts of the world are different from each other. In this, we will investigate the effect of different material combinations on heat and moisture performance of firefighter clothing using heat transfer (flame), heat transfer (radiant), and water vapor resistance tests according to the EN469 test standard which is summarized in Table 1. According to our best knowledge, this will be the first study to also show the effect of washing cycles on performance of the assemblies according to latest EN469 which recommends performing of washing cycles. EN469:2014 Level 2 shows the higher requirement for structural firefighting and is used by professional trained firefighters. 


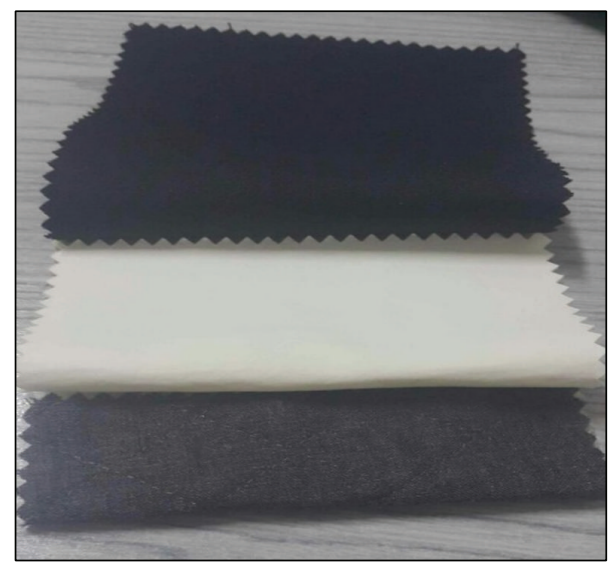

FIGURE 1: Assembly 1 with its three layers.

The following section describes the materials and their combinations as well as test equipment and methods. The third part reports the results obtained from the experimental procedure and discussion of heat and moisture transfer properties of the fabric assemblies.

\section{Materials and Methods}

In this study, different types of fabrics were combined to make a multilayered fabric assembly for firefighter turnout suits. Four types of outer shell fabrics, four types of moisture barrier fabrics, and four types of heat barriers with different weights and materials' compositions were chosen for the experimental study. Characteristics of the materials are listed in Table 2.

In this study five types of material assemblies were created as Assembly 1, Assembly 2, Assembly 3, Assembly 4, and Assembly 5 considering market demand in terms of protection and cost issues. Figure 1 shows the image of protective fabric structure of Assembly 1 with its three layers.

2.1. Heat Protection Performance. Thermal protective performance of the multilayered fabric assemblies was tested according to EN-469:2014 6.3 and 6.4. In order to evaluate the behavior of the fabrics, the heat flux density was arranged to $80 \mathrm{~kW} / \mathrm{m}^{2}$ and $40 \mathrm{~kW} / \mathrm{m}^{2}$ for heat transfer-flame test and heat transfer radiation using WAZAU TPP DIN ISO 9151 and HBP DIN ISO 6942 instruments, respectively (Figure 2). The heat flux density represents the amount of energy incident per unit time on the exposed face of the specimen. The heat protection properties of the multilayer fabrics were determined by measuring the amount of the time to reach a temperature increase of 12 or $24^{\circ} \mathrm{C}$ in a calorimeter according to the applied latest standard. Heat protection performance tests determine the threshold of pain in which first degree of burn occurs as well as the moment that second-degree burns originate and the reaction time (the time between $\mathrm{RHTI}_{12}$ and $\mathrm{RHTI}_{24}$ ).

The washing tests were performed for five washing cycles according to ISO 6330:2012 (6N/A) * 5. After washing tests, heat transfer-flame test and heat transfer radiation tests were repeated owing to the updated EN-469:2014 6.3 and 6.4 Standard. Prior to testing, all the specimens were conditioned for $24 \mathrm{H}$ at a temperature of $(20 \pm 2)^{\circ} \mathrm{C}$ and relative humidity of $(65 \pm 2) \%$. The evaluation of the test results was presented by Heat Transfer Index (HTI) where it shows the calculated mean time in seconds to achieve a temperature rise of $(24 \pm 2)^{\circ} \mathrm{C}$ when testing by these instruments.

2.2. Water Vapor Resistance Performance. The water vapor resistance performance of the multilayered fabric assemblies was tested according to EN-469:2014 6.13 using sweating guarded-hotplate instruments from MTNW SGHP-8.2 as seen in Figure 3. The test conditions were set to $35^{\circ} \mathrm{C}, 40 \%$ $\mathrm{RH}$, and $1.00 \mathrm{~m} / \mathrm{s}$. The tests were repeated after five washing cycles performed according to ISO 6330:2012 (6N/A) * 5. During the tests, the specimen was placed on an electrically heated plate with conditioned air ducted flow across and parallel to its surface. Water fed to the heated plate evaporates and passes as vapor through the liquid-water impermeable membrane which the specimen was placed over it. The heat flux is given to the plate to keep the temperature constant at the plate with the test specimen placed on the membrane, which represents a measure of the rate of water evaporation in accordance with water vapor resistance.

\section{Results}

During the firefighting or physical exercise of the firefighter, the heat resistance and the water permeability of the protective garment worn by the firefighter should be higher in order to meet standard's requirements. Therefore, the material combinations in terms of thermal protection as well as comfort issues should be optimized well. The thermal protective performance of the assemblies mentioned in this study was examined according to conducted heat transferflame tests and heat transfer-radiation tests. Thereafter, the assemblies satisfying thermal protection were evaluated by conducting the water vapour resistance tests for comfort aspects. For instance, Assembly 1 and Assembly 3 subjected to tests are shown in Figure 4.

Since effect of the washing cycles on performance of the protective clothing is one of the major aims of this study, statistical analysis has also been applied in order to see whether washing cycles affect performance of the clothing or not. $t$-test was used to compare samples before and after being subjected to washing cycles. $P$ values were calculated through the $t$-test and results were discussed.

3.1. Heat Transfer-Radiation Test Results of the Multilayered Assemblies. Table 3 lists the results of the heat transfer radiation index $\mathrm{RHTI}_{24}$ (the time to reach a temperature increase of $24^{\circ} \mathrm{C}$ ) and the difference $\mathrm{RHTI}_{24-12}$ (indication of the skin pain alarm time) for assembly configurations. The measurements were repeated three times for each kind of combination according to standard and the index obtained at each single test is significantly important for evaluation. Thus, it should be noted that the performance of the specimens was classified according to the lowest single result on the basis of EN-469 test standard. 


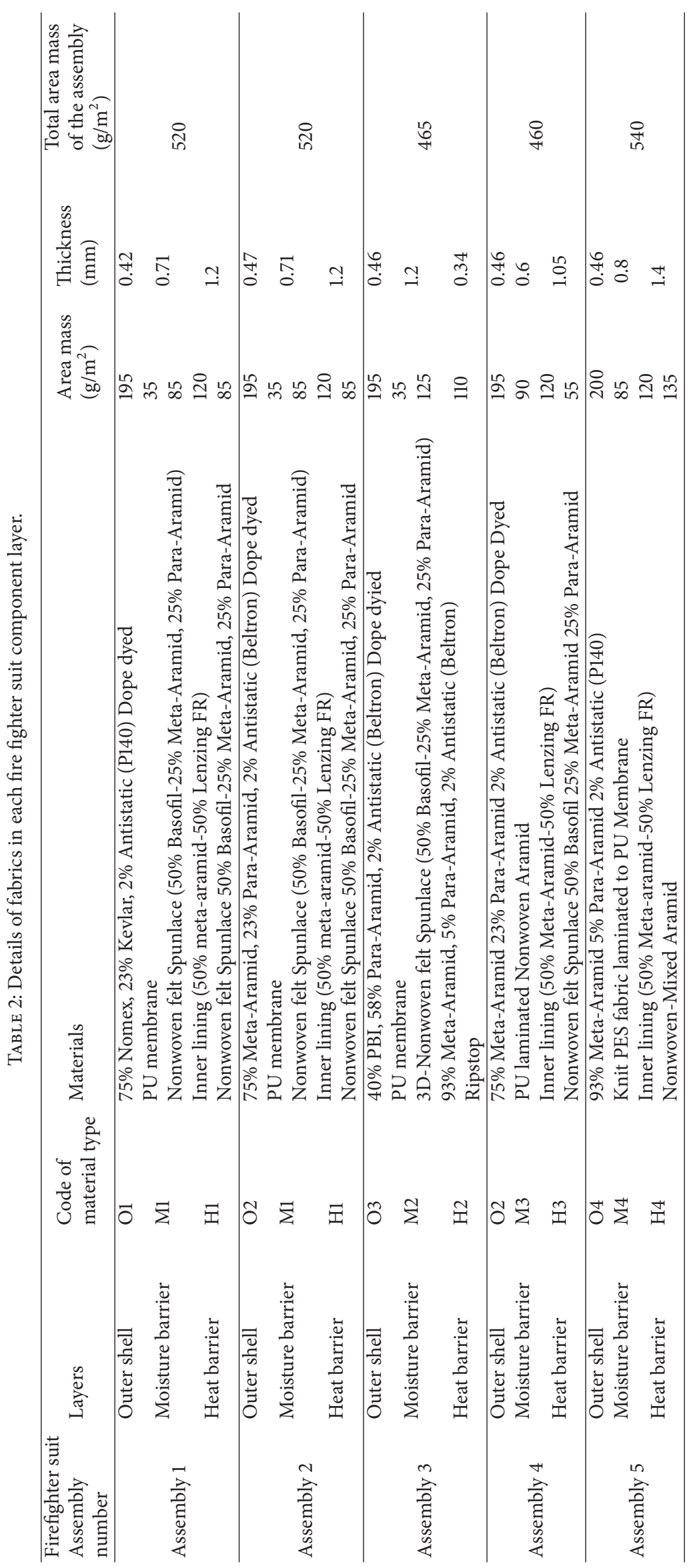


TABLE 3: Heat transfer-radiation test results of multilayered fabric assemblies.

\begin{tabular}{|c|c|c|c|c|c|c|c|c|}
\hline \multirow{2}{*}{ Assembly number } & & \multirow{2}{*}{ Index } & \multirow{2}{*}{ Test 1} & \multirow{2}{*}{ Test 2} & \multirow{2}{*}{ Test 3} & \multicolumn{2}{|c|}{$P$ value } & \multirow{2}{*}{ Level } \\
\hline & & & & & & $\mathrm{RHTI}_{24}$ & RHTI $_{24-12}$ & \\
\hline \multirow{4}{*}{ Assembly 1} & \multirow{2}{*}{ Before washing } & $\mathrm{RHTI}_{24}$ & 20.8 & 20.5 & 20.5 & \multirow{4}{*}{0.064} & \multirow{4}{*}{0.373} & $X 2$ \\
\hline & & $\mathrm{RHTI}_{24-12}$ & 6.1 & 6.0 & 5.9 & & & $X 2$ \\
\hline & \multirow{2}{*}{ After washing } & $\mathrm{RHTI}_{24}$ & 20.4 & 20.4 & 20.3 & & & $X 2$ \\
\hline & & $\mathrm{RHTI}_{24-12}$ & 6.0 & 5.9 & 5.9 & & & $X 2$ \\
\hline \multirow{4}{*}{ Assembly 2} & \multirow{2}{*}{ Before washing } & $\mathrm{RHTI}_{24}$ & 22.5 & 22.4 & 22.4 & \multirow{4}{*}{0.014} & \multirow{4}{*}{0.374} & $X 2$ \\
\hline & & $\mathrm{RHTI}_{24-12}$ & 6.7 & 6.5 & 6.6 & & & $X 2$ \\
\hline & \multirow{2}{*}{ After washing } & $\mathrm{RHTI}_{24}$ & 22.2 & 21.9 & 21.9 & & & $X 2$ \\
\hline & & $\mathrm{RHTI}_{24-12}$ & 6.6 & 6.5 & 6.5 & & & $X 2$ \\
\hline \multirow{4}{*}{ Assembly 3} & \multirow{2}{*}{ Before washing } & $\mathrm{RHTI}_{24}$ & 22.3 & 22.6 & 22.6 & \multirow{4}{*}{0.274} & \multirow{4}{*}{0.205} & $X 2$ \\
\hline & & $\mathrm{RHTI}_{24-12}$ & 7.6 & 7.9 & 7.7 & & & $X 2$ \\
\hline & \multirow{2}{*}{ After washing } & $\mathrm{RHTI}_{24}$ & 22.4 & 22.3 & 22.4 & & & $X 2$ \\
\hline & & $\mathrm{RHTI}_{24-12}$ & 7.6 & 7.6 & 7.6 & & & $X 2$ \\
\hline \multirow{4}{*}{ Assembly 4} & \multirow{2}{*}{ Before washing } & $\mathrm{HTI}_{24}$ & 20.4 & 20.3 & 20.2 & \multirow{4}{*}{0.016} & \multirow{4}{*}{0.020} & $X 2$ \\
\hline & & $\mathrm{HTI}_{24-12}$ & 6.4 & 6.4 & 6.5 & & & $X 2$ \\
\hline & \multirow{2}{*}{ After washing } & $\mathrm{HTI}_{24}$ & 20.1 & 20 & 20 & & & $X 2$ \\
\hline & & $\mathrm{HTI}_{24-12}$ & 6.3 & 6.2 & 6.3 & & & $X 2$ \\
\hline \multirow{4}{*}{ Assembly 5} & \multirow{2}{*}{ Before washing } & $\mathrm{HTI}_{24}$ & 24.6 & 24.5 & 24.7 & \multirow{4}{*}{0.001} & \multirow{4}{*}{0.007} & $X 2$ \\
\hline & & $\mathrm{HTI}_{24-12}$ & 7.6 & 7.8 & 7.8 & & & $X 2$ \\
\hline & \multirow{2}{*}{ After washing } & $\mathrm{HTI}_{24}$ & 23.9 & 24.0 & 23.9 & & & $X 2$ \\
\hline & & $\mathrm{HTI}_{24-12}$ & 7.3 & 7.4 & 7.4 & & & $X 2$ \\
\hline
\end{tabular}

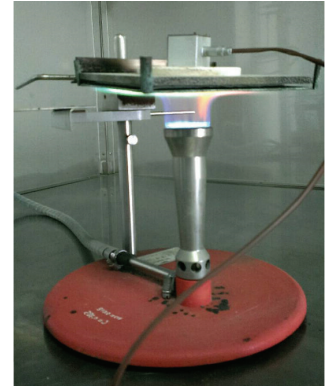

(a)

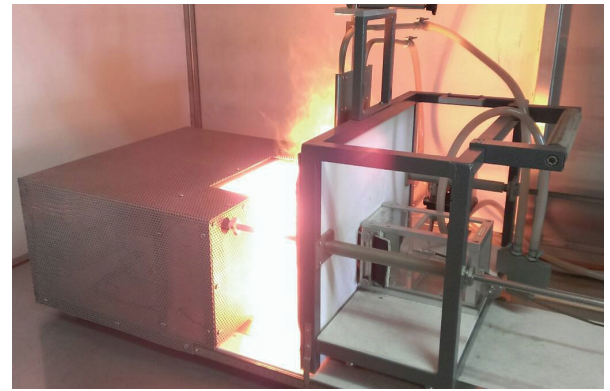

(b)

FIgURE 2: Measurements for thermal protective performance (a) specimen when exposed to flame using WAZAU TPP DIN ISO 9151 instrument (b) specimen when exposed to a source of radiant heat WAZAU HBP DIN ISO 6942 instrument.

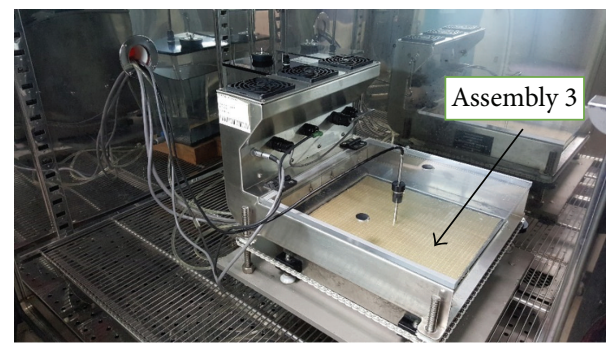

FIGURE 3: Water vapour resistance measurement using sweating guarded-hotplate test.

As seen in Table 3, all assemblies have obviously presented radiant protection with Level 2 which is the higher requirement for structural firefighting that is used by professional trained firefighters. Moreover, it was observed that the performances of the assemblies generally showed a slight decrease after washing as it is expected due to the mainly decreasing level of functional finishes. However, Assembly 4 and Assembly 5 showed significant difference according to the $P$ values as shown in Table 3 . In addition, Assembly 5 showed the highest radiant protection among samples with the 24.7 and 7.8 seconds for $\mathrm{HTI}_{24}$ and $\mathrm{HTI}_{24-12}$, respectively. This may be attributed to its higher total area mass of multilayer structures.

When Assembly 1 and Assembly 2 are taken into consideration, their moisture barrier and thermal heat barrier have the identical material content and structural properties. Although the materials content of the outer shells is the same for these two assemblies, they differentiated regarding the material brand and this varied outer shell thickness. Thus, outer shell with higher thickness, that is, $0.47 \mathrm{~mm}$ for Assembly 2, showed better heat protection compared with Assembly 1. 

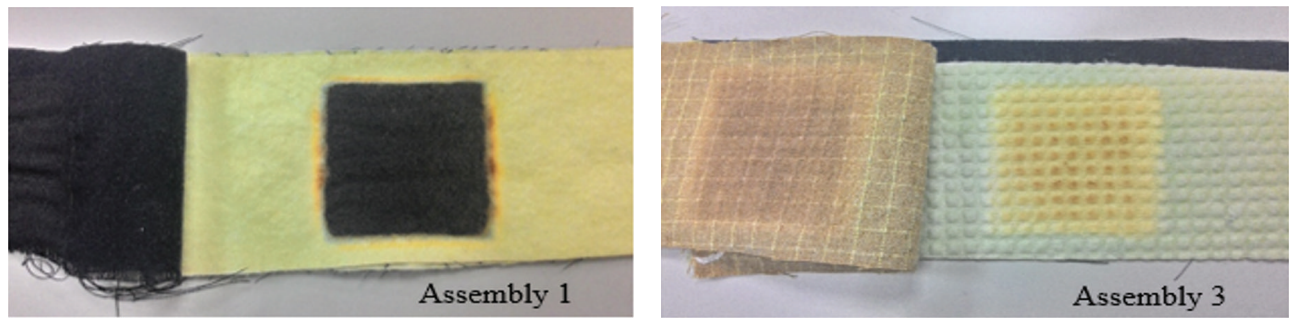

FIgURE 4: Images of Assembly 1 and Assembly 3 after being exposed to a source of radiant heat.

TABLE 4: Heat transfer-flame test results of multilayered fabric assemblies.

\begin{tabular}{|c|c|c|c|c|c|c|c|c|}
\hline \multirow{2}{*}{ Assembly number } & & \multirow{2}{*}{ Index } & \multirow{2}{*}{ Test 1} & \multirow{2}{*}{ Test 2} & \multirow{2}{*}{ Test 3} & \multicolumn{2}{|c|}{$P$ value } & \multirow{2}{*}{ Level } \\
\hline & & & & & & $\mathrm{HTI}_{24}$ & $\mathrm{HTI}_{24-12}$ & \\
\hline \multirow{4}{*}{ Assembly 1} & \multirow{2}{*}{ Before washing } & $\mathrm{HTI}_{24}$ & 17.7 & 17.9 & 18.1 & \multirow{4}{*}{0.006} & \multirow{4}{*}{0.025} & $X 2$ \\
\hline & & $\mathrm{HTI}_{24-12}$ & 4.7 & 4.8 & 4.9 & & & $X 2$ \\
\hline & \multirow{2}{*}{ After washing } & $\mathrm{HTI}_{24}$ & 17.2 & 17.3 & 17.3 & & & $X 2$ \\
\hline & & $\mathrm{HTI}_{24-12}$ & 4.6 & 4.6 & 4.6 & & & $X 2$ \\
\hline \multirow{4}{*}{ Assembly 2} & \multirow{2}{*}{ Before washing } & $\mathrm{HTI}_{24}$ & 18.7 & 18.7 & 18.8 & \multirow{4}{*}{0.005} & \multirow{4}{*}{0.101} & $X 2$ \\
\hline & & $\mathrm{HTI}_{24-12}$ & 5.0 & 4.9 & 5.0 & & & $X 2$ \\
\hline & \multirow{2}{*}{ After washing } & $\mathrm{HTI}_{24}$ & 18.4 & 18.3 & 18.5 & & & $X 2$ \\
\hline & & $\mathrm{HTI}_{24-12}$ & 4.9 & 4.8 & 4.9 & & & $X 2$ \\
\hline \multirow{4}{*}{ Assembly 3} & \multirow{2}{*}{ Before washing } & $\mathrm{HTI}_{24}$ & 16.5 & 16.1 & 16.3 & \multirow{4}{*}{0.008} & \multirow{4}{*}{0.140} & $X 2$ \\
\hline & & $\mathrm{HTI}_{24-12}$ & 4.1 & 3.9 & 4.0 & & & $\mathrm{X} 1$ \\
\hline & \multirow{2}{*}{ After washing } & $\mathrm{HTI}_{24}$ & 15.0 & 14.8 & 15.1 & & & $X 2$ \\
\hline & & $\mathrm{HTI}_{24-12}$ & 3.6 & 3.6 & 4.0 & & & $\mathrm{X} 1$ \\
\hline \multirow{4}{*}{ Assembly 4} & \multirow{2}{*}{ Before washing } & $\mathrm{HTI}_{24}$ & 14.1 & 14.3 & 13.7 & \multirow{4}{*}{0.130} & \multirow{4}{*}{0.274} & $X 2$ \\
\hline & & $\mathrm{HTI}_{24-12}$ & 3.9 & 4.1 & 3.6 & & & $\mathrm{X} 1$ \\
\hline & \multirow{2}{*}{ After washing } & $\mathrm{HTI}_{24}$ & 13.8 & 13.7 & 13.3 & & & $X 2$ \\
\hline & & $\mathrm{HTI}_{24-12}$ & 3.7 & 3.8 & 3.3 & & & $\mathrm{X} 1$ \\
\hline \multirow{4}{*}{ Assembly 5} & \multirow{2}{*}{ Before washing } & $\mathrm{HTI}_{24}$ & 15.1 & 15.2 & 14.9 & \multirow{4}{*}{0.155} & \multirow{4}{*}{0.105} & $X 2$ \\
\hline & & $\mathrm{HTI}_{24-12}$ & 4.1 & 4.1 & 3.9 & & & $\mathrm{X} 1$ \\
\hline & \multirow{2}{*}{ After washing } & $\mathrm{HTI}_{24}$ & 14.8 & 14.9 & 14.1 & & & $X 2$ \\
\hline & & $\mathrm{HTI}_{24-12}$ & 3.9 & 3.9 & 3.68 & & & $\mathbf{X 1}$ \\
\hline
\end{tabular}

Despite the usage of the same outer shell (O2) in Assembly 2 and Assembly 4, the results also showed differences due to the change in moisture barrier and heat barrier. Even though the heat barriers' material contents of the structures are the same, their weights are different from each other. These differences caused variation in total thickness and mass. In this case, Assembly 2 has higher mass and thickness compared with Assembly 4 and this yielded higher radiant heat performance. Thus, differences in overall weight of the structure may result in increased level of radiant heat performance.

3.2. Heat Transfer-Flame Test Results of the Multilayered Assemblies. With reference to Table 4, it is clearly observed that only Assembly 1 and Assembly 2 showed protection against flame in accordance with level 2 according to the applied standard while the rest of the assemblies showed protection against flame in accordance with level 1.
Outermost layer of the assemblies has proximal contact with flame unlike test. Therefore, the temperature increase in the outer hell structure was probably much higher during the heat flame test at $80 \mathrm{~kW} / \mathrm{m}^{2}$ than during radiant heat test at $40 \mathrm{~kW} / \mathrm{m}^{2}$. Thus, the overall heat protection performances of the structures present lower performance values compared to radiant test results. In all cases, washing cycles have also deteriorating effect on heat protection performance similar to aforementioned radiant heat test results. However, it was found that only results of Assembly 1 showed significant difference in $\mathrm{HTI}_{24}$ and $\mathrm{HTI}_{24-12}$ tests. Assembly 2 and Assembly 3 showed significant difference only in $\mathrm{HTI}_{24}$ test.

Although the meta-aramid fibre content of the outer shell fabric of Assembly 5 is higher than Assembly 2 and Assembly 3, it was expected to show higher heat protection performance for flame test. This assumption has also been proven in previous works $[25,27]$. However, during the experimental tests it was found that Assembly 5 demonstrated 
TABLE 5: Water vapour resistance test results of multilayered fabric assemblies.

\begin{tabular}{llccc}
\hline $\begin{array}{l}\text { Assembly } \\
\text { number }\end{array}$ & & $\begin{array}{c}\text { Mean water } \\
\text { vapour } \\
\text { resistance, } \\
\mathrm{RET} \\
\left(\mathrm{m}^{2} \mathrm{~Pa} / \mathrm{W}\right)\end{array}$ & $P$ values & Level \\
\hline Assembly 1 & $\begin{array}{l}\text { Before } \\
\text { washing } \\
\text { After washing }\end{array}$ & 28.85 & 0.0003 & $\mathrm{Z2}$ \\
\hline & $\begin{array}{l}\text { Before } \\
\text { washing } \\
\text { Assembly 2 }\end{array}$ & 29.61 & & $\mathrm{Z} 2$ \\
\hline & After washing & 27.51 & 0.0010 & $Z 2$ \\
\hline
\end{tabular}

lower performance even though it has a higher overall mass. This can be attributed to the brand differences which may have significant effect on the protection performance of the selected fibers. Comparing Assembly 1 and Assembly 2 can also prove this phenomenon with respect to outer shell fabric.

3.3. Water Vapor Resistance Results of the Multilayered Assemblies. The assemblies satisfying thermal protection, namely, Assembly 1 and Assembly, were further evaluated by performing the water vapour resistance tests for comfort aspects. In this case, water vapour resistance (RET) of clothing indicates how well it can transport water vapour to the environment, which affects the thermal comfort during firefighting [30]. Table 3 shows the RET values of samples with respect to any additional treatment and washing cycles. According to Table 3, the RET values in all cases are lower than $\leq 30 \mathrm{~m}^{2} \mathrm{~Pa} / \mathrm{W}$, which is the requirement for level 2 . Thus, these 2 assemblies show good water vapour permeability which is crucial property for the design of firefighting clothing. In addition, it was observed that the water vapour resistance of the samples decreases with washing. In other words, the water vapor transmission within the fabric structures becomes easier due to the decreasing of fabric finishing as well deformation of the fabric structure, and this leads to fabric structure to be felt more comfortable by the user. This can be seen from Table 5. According to the $P$ values $(P<0.05)$, there is significant difference between washed samples and unwashed samples in terms of water vapour resistance test results.

\section{Conclusions}

In this research study, the effects of different material combinations on heat and moisture performance of the firefighter clothing were investigated using heat transfer (flame), heat transfer (radiant), and water vapor resistance tests according to the EN469 test standard. While washing test has detrimental effect on heat protection performance, it improved water vapor transmission of the samples that is beneficial for the comfort of the wearers. Also, the overall material weight of the layers has improving effect on the radiant heat protection level; however, fabric assemblies according to their brand have showed different kind of protection levels independent from their material weight. Thus, it cannot be stated that there is a positive correlation between heat protection level and materials' weight. This can be true to some extent if the brands of the fabric layer are chosen as identical. While all the samples presented high level of protection when they are exposed to radiant heat, they presented reduced protection levels for heat transfer-flame test. This can be obviously attributed to proximal contact of samples with the flame. Overall, Assembly 1 and Assembly 2 showed better performance properties in terms of comfort and heat protection.

\section{Conflict of Interests}

The authors declare no conflict of interests.

\section{Acknowledgments}

This project has received funding from the European Union's Horizon 2020 research and innovation programme under the Marie Skłodowska-Curie Grant agreement no. 644268. The paper describes the part of the project which was realized by the Department of Textile Engineering of ITU and Department of Testing and Certification of Taiwan Textile Research Institute, and R\&D Department of Kivanc Group.

\section{References}

[1] R. Funnell, G. Koutoukidis, and K. Lawrence, "Vital signals," in Tabbner's Nursing Care: Theory and Practice, pp. 251-252, Elsevier, Chatswood, Australia, 2008.

[2] K. Parsons, Human Thermal Environments: The Effects of Hot, Moderate, and Cold Environments on Human Health, Comfort, and Performance, CRC Press, 2014.

[3] G. P. Kenny and A. D. Flouris, "The human thermoregulatory system and its response to thermal stress," in Protective Clothing: Managing Thermal Stress, F. Wang and C. Gao, Eds., pp. 319-349, Woodhead, Cambridge, UK, 2014.

[4] W. A. Lotens and G. Havenith, "Calculation of clothing insulation and vapour resistance," Ergonomics, vol. 34, no. 2, pp. 233254, 1991.

[5] D. L. Smith, J. P. DeBlois, and S. N. Kales, "Combatting sudden cardiac death (SCD) in the United States (US) fire service," International Fire Service Journal of Leadership \& Management, vol. 8, pp. 23-30, 2014.

[6] A. Bouchama and J. P. Knochel, "Medical progress: heat stroke," The New England Journal of Medicine, vol. 346, no. 25, pp. 19781988, 2002.

[7] N. R. Gavva, "Body-temperature maintenance as the predominant function of the vanilloid receptor TRPV1," Trends in Pharmacological Sciences, vol. 29, no. 11, pp. 550-557, 2008.

[8] C. T. M. Davies, "Thermoregulation during exercise in relation to sex and age," European Journal of Applied Physiology and Occupational Physiology, vol. 42, no. 2, pp. 71-79, 1979.

[9] Y. Houdas and E. F. J. Ring, Human Body Temperature, Springer Science \& Business Media, 1982.

[10] R. Nayak, S. Houshyar, and R. Padhye, "Recent trends and future scope in the protection and comfort of fire-fighters' personal protective clothing," Fire Science Reviews, vol. 3, no. 1, article 4, 19 pages, 2014.

[11] W. E. Mell and J. R. Lawson, "A heat transfer model for firefighters' protective clothing," Fire Technology, vol. 36, no. 1, pp. 39-68, 2000. 
[12] L. K. Lawson, E. M. Crown, M. Y. Ackerman, and J. D. Dale, "Moisture effects in heat transfer through clothing systems for wildland firefighters," International Journal of Occupational Safety and Ergonomics, vol. 10, no. 3, pp. 227-238, 2004.

[13] R. L. Barker, C. Guerth-Schacher, R. V. Grimes, and H. Hamouda, "Effects of moisture on the thermal protective performance of firefighter protective clothing in low-level radiant heat exposures," Textile Research Journal, vol. 76, no. 1, pp. 27-31, 2006.

[14] L. K. Lawson, E. M. Crown, M. Y. Ackerman, and J. Douglas Dale, "Moisture effects in heat transfer through clothing systems for wildland firefighters," International Journal of Occupational Safety and Ergonomics, vol. 10, no. 3, pp. 227-238, 2004.

[15] G. Song, S. Paskaluk, R. Sati, E. M. Crown, J. D. Dale, and M. Ackerman, "Thermal protective performance of protective clothing used for low radiant heat protection," Textile Research Journal, vol. 81, no. 3, pp. 311-323, 2011.

[16] A. Shaw, "Selection of flame resistant protective clothing," in Handbook of Fire Resistant Textiles, pp. 351-363, Woodhead, 2013.

[17] D. Jiang, C. Sun, Y. Zhou et al., "Enhanced flame retardancy of cotton fabrics with a novel intumescent flame-retardant finishing system," Fibers and Polymers, vol. 16, no. 2, pp. 388396, 2015.

[18] D. Hofmann, K.-A. Wartig, R. Thomann, B. Dittrich, B. Schartel, and R. Mülhaupt, "Functionalized graphene and carbon materials as additives for melt-extruded flame retardant polypropylene," Macromolecular Materials and Engineering, vol. 298, no. 12, pp. 1322-1334, 2013.

[19] N. Mao, "High performance textiles for protective clothing," in High Performance Textiles and their Applications, chapter 3, pp. 91-143, Elsevier, 2014.

[20] R. Shishoo, "Recent developments in materials for use in protective clothing," International Journal of Clothing Science and Technology, vol. 14, no. 3-4, pp. 201-215, 2002.

[21] Effect of Para-Aramid on Performance of Firefighting Clothing. (n.d.). Retrieved May 11, 2015, http://www.dupont.co.uk/products-and-services/personal-protective-equipment/thermalprotective-apparel-accessories/articles/nomex-firefighting-clothing.html.

[22] J. R. Lawson, "Fire fighters' protective clothing and thermal environments of structural fire fighting," ASTM Special Technical Publication 1273, 1997.

[23] S. Mandal, G. Song, M. Ackerman, S. Paskaluk, and F. Gholamreza, "Characterization of textile fabrics under various thermal exposures," Textile Research Journal, vol. 83, no. 10, pp. 10051019, 2013.

[24] Z. Cui and W. Zhang, "Study of the effect of material assembly on the moisture and thermal protective performance of firefighter clothing," Fibres \& Textiles in Eastern Europe, vol. 77, no. 6, pp. 80-83, 2009.

[25] Z. Fanglong, Z. Weiyuan, and C. Minzhi, "Investigation of material combinations for fire-fighter's protective clothing on radiant protective and heat-moisture transfer performance," Fibres and Textiles in Eastern Europe, vol. 15, no. 1, article 72, 2007.

[26] C. Keiser, C. Becker, and R. M. Rossi, "Moisture transport and absorption in multilayer protective clothing fabrics," Textile Research Journal, vol. 78, no. 7, pp. 604-613, 2008.

[27] G. Song, W. Cao, and F. Gholamreza, "Analyzing stored thermal energy and thermal protective performance of clothing," Textile Research Journal, vol. 81, no. 11, pp. 1124-1138, 2011.
[28] R. M. Rossi and T. Zimmerli, "Influence of humidity on the radiant, convective and contact heat transmission through protective clothing materials," ASTM Special Technical Publication 1237, ASTM International, West Conshohocken, Pa, USA, 1996.

[29] H. Makinen, "Firefigter's protective clothing," in Textiles for Protection, R. A. Scott, Ed., pp. 622-648, Elsevier, 2005.

[30] K. Prasad, W. H. Twilley, and J. R. Lawson, Thermal Performance of Fire Fighters' Protective Clothing: Numerical Study of Transient Heat and Water Vapor Transfer, US Department of Commerce, Technology Administration, National Institute of Standards and Technology, Gaithersburg, Md, USA, 2002. 

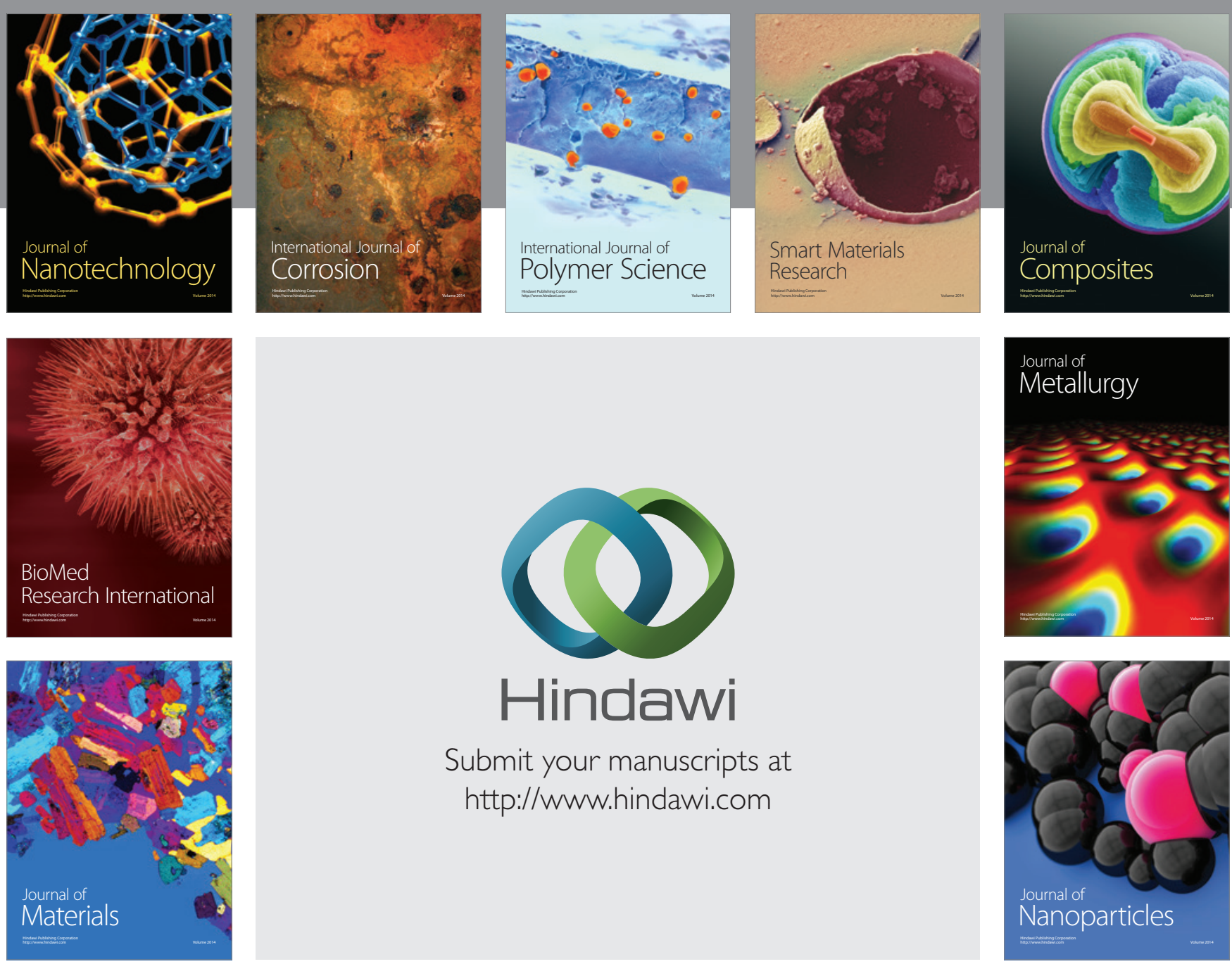

Submit your manuscripts at http://www.hindawi.com
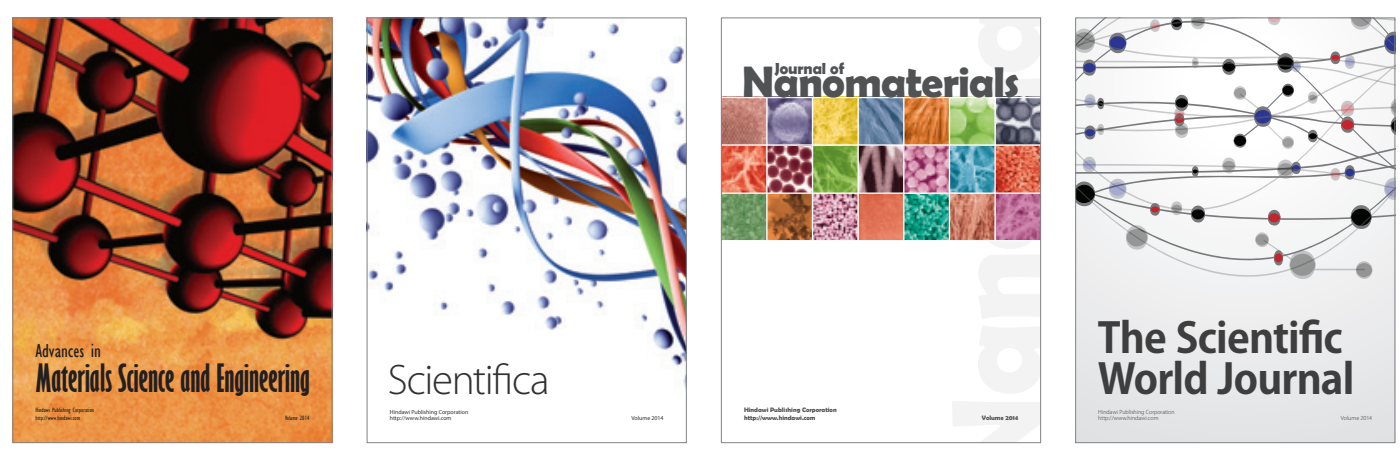

\section{The Scientific World Journal}
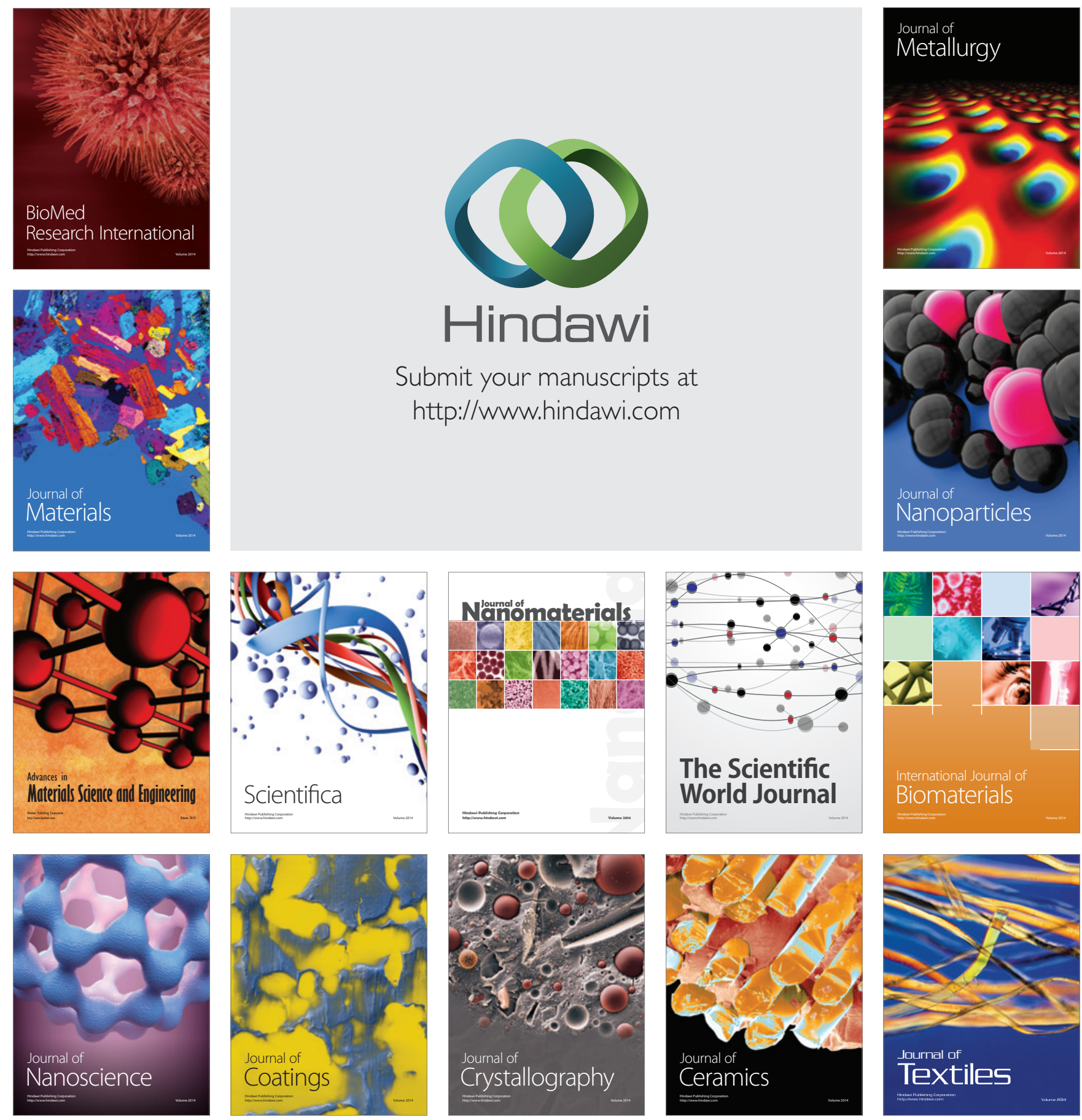